\title{
Impeller Design of a Centrifugal Fan with Blade Optimization
}

\author{
Yu-Tai Lee, ${ }^{1}$ Vineet Ahuja, ${ }^{2}$ Ashvin Hosangadi, ${ }^{2}$ Michael E. Slipper, ${ }^{3}$ Lawrence P. Mulvihill, ${ }^{1}$ \\ Roger Birkbeck, ${ }^{2}$ and Roderick M. Coleman ${ }^{1}$ \\ ${ }^{1}$ Carderock Division, Naval Surface Warfare Center, Code 5700, West Bethesda, MD 20817, USA \\ ${ }^{2}$ Combustion Research and Flow Technology, Inc. (CRAFT Tech), Pipersville, PA 18947, USA \\ ${ }^{3}$ Ships Systems Engineering Station, Carderock Division, Naval Surface Warfare Center, Code 9860, Philadelphia, PA 19112, USA
}

Correspondence should be addressed to Yu-Tai Lee, yu.lee@navy.mil

Received 1 December 2010; Revised 12 May 2011; Accepted 14 June 2011

Academic Editor: Meinhard Taher Schobeiri

Copyright (C) 2011 Yu-Tai Lee et al. This is an open access article distributed under the Creative Commons Attribution License, which permits unrestricted use, distribution, and reproduction in any medium, provided the original work is properly cited.

\begin{abstract}
A method is presented for redesigning a centrifugal impeller and its inlet duct. The double-discharge volute casing is a structural constraint and is maintained for its shape. The redesign effort was geared towards meeting the design volute exit pressure while reducing the power required to operate the fan. Given the high performance of the baseline impeller, the redesign adopted a high-fidelity CFD-based computational approach capable of accounting for all aerodynamic losses. The present effort utilized a numerical optimization with experiential steering techniques to redesign the fan blades, inlet duct, and shroud of the impeller. The resulting flow path modifications not only met the pressure requirement, but also reduced the fan power by $8.8 \%$ over the baseline. A refined CFD assessment of the impeller/volute coupling and the gap between the stationary duct and the rotating shroud revealed a reduction in efficiency due to the volute and the gap. The calculations verified that the new impeller matches better with the original volute. Model-fan measured data was used to validate CFD predictions and impeller design goals. The CFD results further demonstrate a Reynolds-number effect between the model- and full-scale fans.
\end{abstract}

\section{Introduction}

A heavy-duty air cushion vehicle usually employs centrifugal lift fans to pressurize the air cushion and power the steering thruster. The design of the lift fan system is subject to meet payload, machinery spacing, and ruggedness requirements [1]. The current low-specific-speed $(\approx$ 0.2 ) baseline lift-fan impeller (named the B\#1 impeller in the present paper) shown in Figure 1 is fitted with a doubledischarge volute (DDV) shown in Figure 2 to provide air for both cushion lift and thrust vectoring. The impeller is a double-width, double-inlet (DWDI) centrifugal type with two nonstaggered blade rows. Each impeller blade row has backward-swept blades mounted between a common back plate and shrouds. In order to effectively manage the craft fuel consumption, a reduction in fan's operating power is necessary. Since the DDV is a structural constraint and required to be maintained in its shape, the baseline impeller and a dual bellmouth (or inlet duct) assembly are therefore redesigned to improve the fan performance. In addition to the baseline impeller, there is an existing reference impeller (named the $\mathrm{B} \# 2$ impeller) which provides further performance comparisons in reference to the baseline. In this paper, a systematic numerical study was carried out of the aerodynamic characteristics of the existing impellers. The study revealed that although the existing impellers were high performing to start with, there was some margin for improvement. In particular, both impellers were susceptible to flow separations near the leading edge of the blade and near the shroud region where the hub transitioned into the common backplate for the impeller system. Subsequently, a piecemeal approach was taken in the redesign effort and the hub, shroud, and bellmouth as well as the impeller blades were redesigned to improve the performance of the fan system. A variety of different techniques were utilized in the redesign process: for example, the hub was modified by streamline tracing; the bellmouth/shroud was modified by altering the local curvature near the blade whereas a formal genetic algorithm- (GA-) based optimization procedure was used to redesign the blade profile. Experiential steering was 


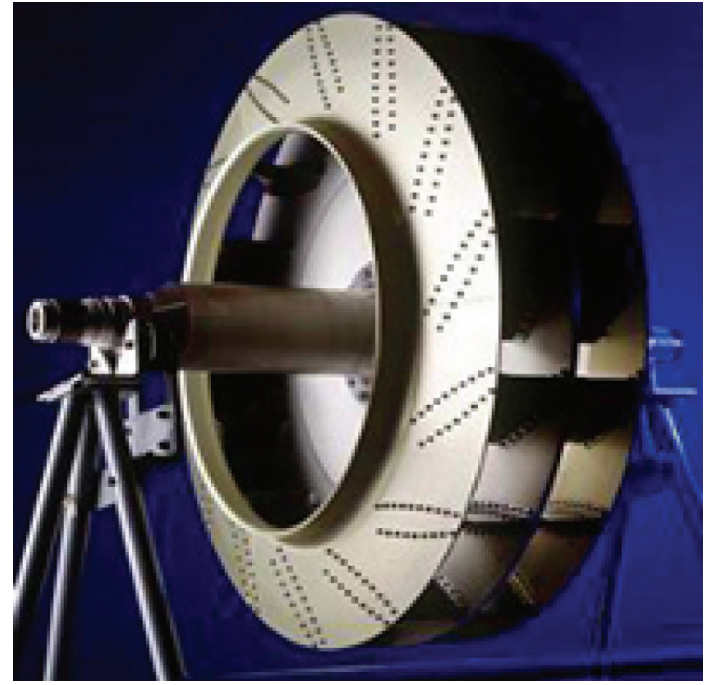

Figure 1: The baseline impeller B\#1.

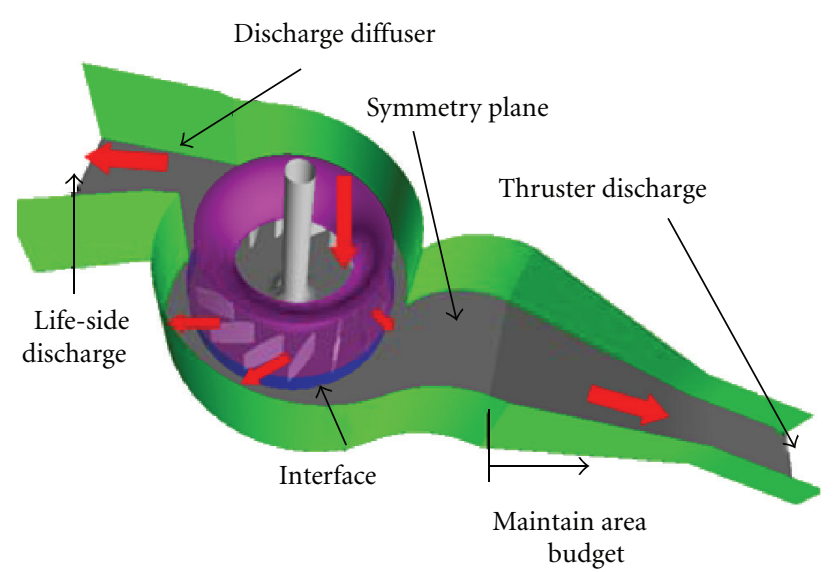

Figure 2: Component representation for a half of the centrifugal fan.

used to alter the optimized two-dimensional blade profile into a three-dimensional swept blade that further enhanced the performance of the impeller.

A detailed study was also carried out of the coupled impeller-volute system. The interaction between the impeller and its associated volute can significantly alter the performance of the impeller. Several groups have reported their findings on the performance of impeller-volute systems. However, the majority of the prior related investigations in the literature dealt with centrifugal impellers and single discharge volutes. For example, Kaupert and Staubli [2] recorded strong blade loading fluctuations as the blade passed the volute tongues on a double spiral volute, particularly at below design flow rates. Hillewaert and Van den Braembussche [3] used numerical predictions of the 3D unsteady inviscid impeller flow interacting with the steady volute flow in centrifugal compressors at off-design conditions and found reasonable agreements with measurements. Lee and Bein [4] also applied steady CFD calculations to a centrifugal refrigerant compressor with an impeller, a vaneless diffuser, and a single discharge volute and obtained a good agreement in volute circumferential pressure with the measurements, particularly the pressure dip at the volute tongue. Meakhail and Park [5], Atif et al. [6], and Karanth and Sharma [7] used both CFD and particle-image-velocity (PIV) measurement to study centrifugal fan impeller interactions with a vaned diffuser and a single discharge volute, and found that their steady numerical simulations were able to predict the flow characteristics, particularly the flow separation, which existed between the impeller and the diffuser. Although all three investigations [5-7] found that their prediction results agree with the measurements, Karanth and Sharma [7] revealed the presence of an optimum radial gap (or the interacting region) which could provide lower interaction losses.

All these aforementioned studies mostly with a single discharge volute indicate a volute feedback to the impeller aerodynamics exists, particularly at the volute tongue location. The current DDV further complicates the flow pattern, shortens the pressure recovery path compared to the single discharge volute, and produces double pressure peaks at two peripheral tongue locations. The significance of the feedback depends, however, on each individual design configuration. Without predefined knowledge of the volute feedback to the impeller performance, impellers from these past efforts [35] were designed without taking the volute feedback into consideration. In our case, since we are primarily interested in performance of the lift fan system, we have catalogued the performance degradation with the addition of a hardconstrained volute. We have carried out the impeller-volute coupling calculations with the use of the frozen impeller approximation which provides a conservative estimate of the performance when compared to fully unsteady simulations.

Lastly, a rigorous design validation study was undertaken with a carefully designed test rig for the $1 / 5$ scale model. Both fans with the existing impellers and the fan system with the redesigned impeller were tested to verify improvement in performance.

In the following sections, we provide details of the strategy and methodology for redesigning the impeller using the impeller-only CFD calculations. Refined CFD calculations coupling the impeller, the volute, and the shroud gap that were used to assess the design and quantify the volute feedback to the impeller performance are discussed after the design procedure. Following that we provide details of the model-scale fan test [8] and comparisons with the coupled CFD predictions at design and off-design conditions. We end the paper with a detailed summary of the redesign process and the lessons learned therewith.

\section{Impeller Aerodynamics for the Existing Impellers}

In order to establish a design strategy within a constrained design window, two existing impellers $\mathrm{B} \# 1$ and $\mathrm{B} \# 2$ were first analyzed with a second-order accurate CFD method which solves a full compressible form of the Navier Stokes equations 
with preconditioning to obtain an efficient time-marching numerical scheme [9] for the incompressible flow. The flow field formulation was implemented within a 3D unstructured code CRUNCH. References [9-12] provide additional details. The CRUNCH CFD code employs a multielement, cell-vertex-based unstructured framework which allows for a combination of tetrahedral, prismatic, and hexahedral cells. The standard high Reynolds number formulation of the $\kappa$ $\varepsilon$ equations forms the basis for the turbulence modelling in CRUNCH. These turbulence equations, with supplemental low Reynolds number correction terms, are given in [10]. Considering the computational efficiency, the wall-function approach was used for the current calculations.

Figure 3 depicts the blade (left figure) and shroud (right figure) arrangements for the 14-bladed B\#1 impeller in black and the 12-bladed B\#2 impeller in gray. The baseline volute shown in Figure 3 is connected to the impeller with a sudden expansion in the flow path area.

Fan aerodynamic performance at the design point requires air at a temperature of $26.7^{\circ} \mathrm{C}$, an impeller shaft speed of $1692 \mathrm{rpm}$, and a shaft power of $1276.6 \mathrm{~kW}\left(=2 \mathrm{PWR}_{\mathrm{ref}}\right)$ to produce a lift static pressure of $7517 \mathrm{~Pa}\left(=P_{\text {ref }}\right)$ at a nominal lift-side air flow rate of $57.43 \mathrm{~m}^{3} / \mathrm{s}$. This results in the following nondimensional parameters:

$$
\text { Lift flow coefficient }=\frac{Q_{\text {lift }}}{1 / 4 \pi D^{2} U}=0.2014
$$

Lift static pressure coefficient $=\frac{\left(P_{s}\right)_{\text {lift }}}{\rho U^{2}}=0.3175$

$$
\text { Power coefficient }=\frac{\text { ShaftPWR }}{1 / 4 \pi \rho D^{2} U^{3}}=0.1892 \text {, }
$$

where $Q_{\text {lift }},\left(P_{s}\right)_{\text {lift }}, D, U$, and $\rho$ are defined as the lift flow rate, fan lift discharge static pressure, fan tip diameter, fan tip speed, and air density, respectively. At the design point, $57 \%$ of the fan air flows through the lift diffuser to maintain the required lift pressure. The goal of the design study is to achieve a reduction in the power coefficient shown in (3) while maintaining the lift-flow characteristics of (1) and (2).

Figure 4 shows the assembly of the bellmouth and impeller for one half of the fan. Due to the geometrical symmetry, the CFD calculations only cover one single blade passage for the gridding system used, as shown in Figure 5. To accurately capture the boundary layer and loading on the blade surface, the grid on the blade portion is structured and all other surfaces are either structured or unstructured as shown in Figure 5. The unstructured cells help to reduce the overall size of the grid thereby reducing turnaround time for the calculations. Although a relatively small gap exists between the rotating shroud and the nonrotating bellmouth, the impeller-only design CFD calculation does not include the effect of the shroud gap flow.

For the incompressible flow calculation, a uniform inflow condition was imposed at the bellmouth inlet to maintain the required flow rate and a mass-averaged back pressure was applied at the impeller exit. A periodic boundary

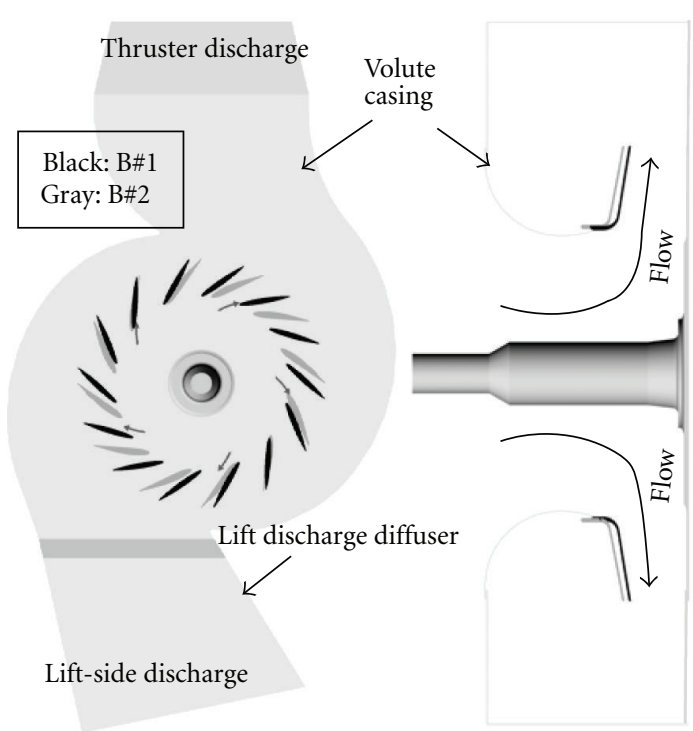

FIgURE 3: Blade/shroud arrangements for impellers B\#1 and B\#2.

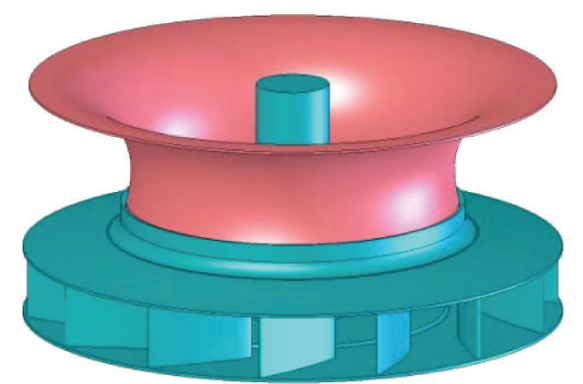

Figure 4: Bellmouth/impeller assembly for the B\#1 impeller.

condition was enforced for the passage boundaries between the blades and a no-slip condition was used at the blade, shroud, backplate, and shaft surfaces. Although the inlet was controlled with a velocity condition, the inlet pressure was predicted as part of the simulation since the pressure pertains to the upstream propagating characteristic. As a consequence, the pressure rise was determined from the difference between the inlet and exit pressures and is a function of the impeller design.

The performance-related parameters, that is, shaft power, output power, and total-to-total efficiency, for the impeller flow field are as follows:

$$
\begin{gathered}
\text { ShaftPWR }=T_{\text {imp }} \cdot \omega, \\
\operatorname{ImpPWR}_{\text {out }}=\left(\Delta P_{t}\right)_{\text {imp }} \cdot Q, \\
\eta_{\text {imp }}=\frac{\text { ImpPWR }_{\text {out }}}{\text { ShaftPWR }}
\end{gathered}
$$

where $T_{\text {imp }}, \omega,\left(\Delta P_{t}\right)_{\text {imp }}$, and $Q$ are the impeller torque, rotational speed, total pressure increase across the bellmouth and the impeller, and the flow rate. The impeller torque was calculated by integrating the forces from the blade, hub, shroud, and backplate. The convergence of the solution is determined by the variation of the calculated impeller torque 


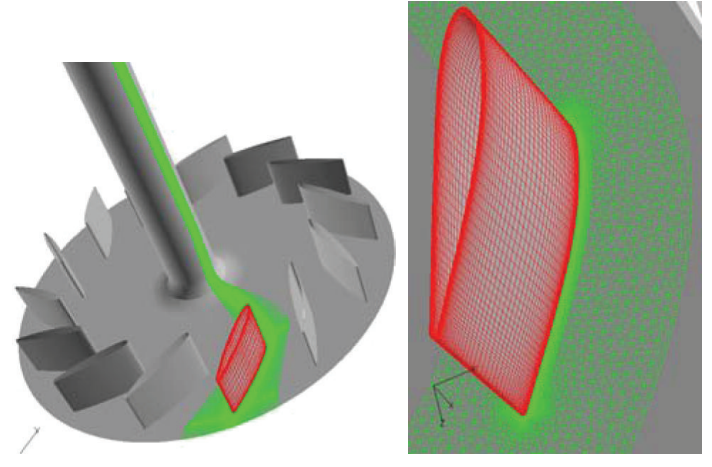

FIGURE 5: Gridding for the impeller B\#1.

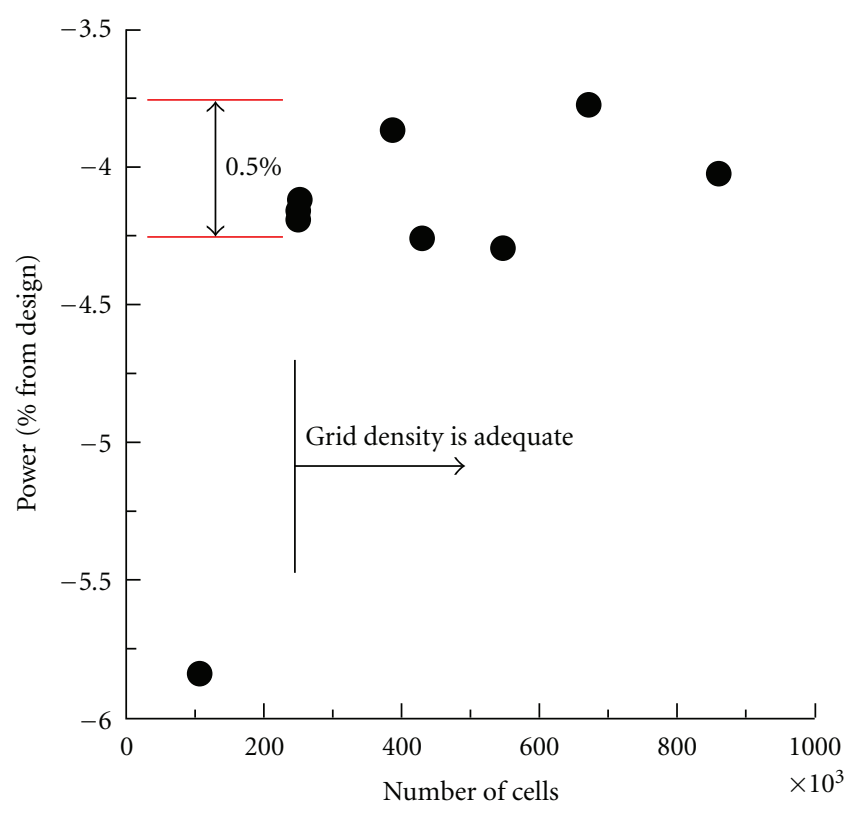

FIgURE 6: Grid density calculations using impeller B\#2.

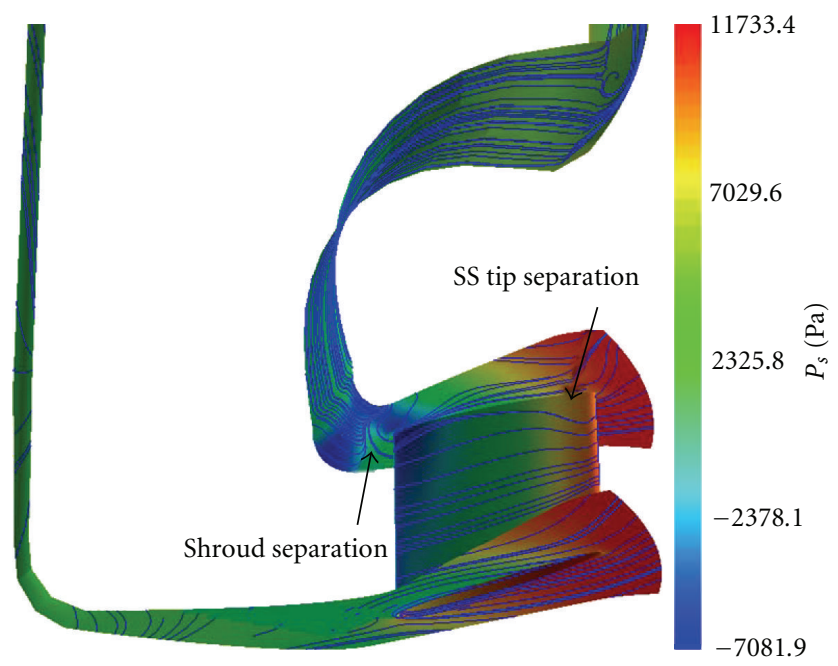

Figure 7: Flow traces near impeller B\#1 surfaces.

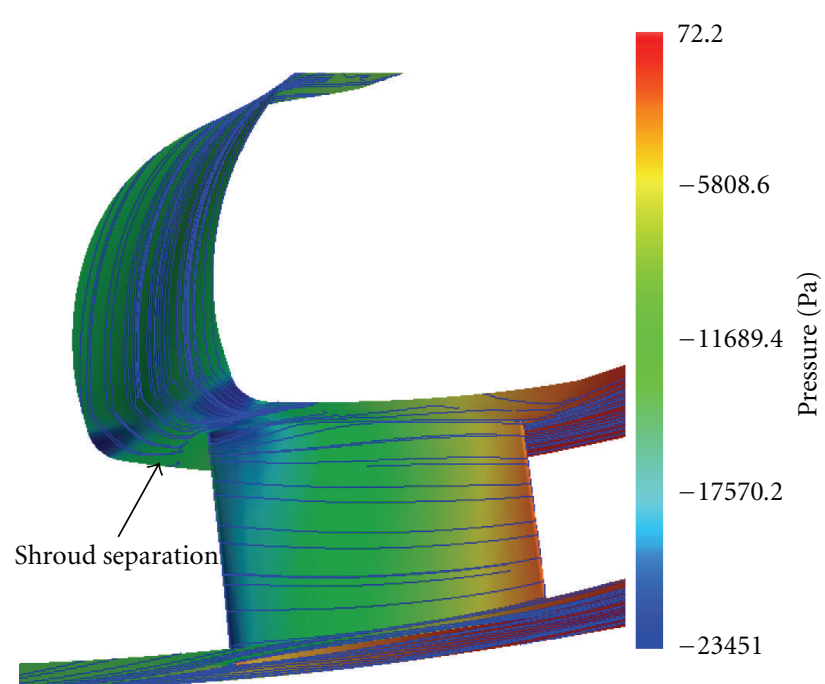

FIgURE 8: Flow traces near B\#2 impeller surfaces.

TABLE 1

\begin{tabular}{lccc}
\hline Impeller & ShaftPWR/PWR & Impeller head $/ P_{\text {ref }}$ & Efficiency $(\%)$ \\
\hline B\#1 & 0.945 & 1.47 & 92.6 \\
B\#2 & 0.960 & 1.52 & 92.9 \\
\hline
\end{tabular}

and the mass-averaged total and static pressure variations at the inlet and outlet planes.

Impeller $\mathrm{B} \# 2$ was used to investigate the grid density requirement. Figure 6 shows the computed percent change in ShaftPWR versus the design power with the number of cells for the structured and unstructured grids ranging from 105,984 to 958,464 cells. The result shows that a grid density of 250,000 cells or more for each impeller blade passage is adequate for a predicted power with an error of $0.5 \%$ (mostly dependent on the grid topology rather than the grid density) or less. Calculations were also performed to investigate the effect of using the wall-function procedure. The grid $y+$ was controlled between 10 and 50 for the wallfunction modelling and below 1 for the near-wall modelling. Calculations were made for both $\mathrm{B} \# 1$ and $\mathrm{B} \# 2$ impellers with an approximately 250,000 cell grid. The predicted ShaftPWR is generally lower for the near-wall modelling, but the difference between the $\mathrm{B} \# 1$ and $\mathrm{B} \# 2$ impellers using the same wall modelling is almost the same between the two models studied.

Figure 7 shows the predicted flow pattern through impeller B\#1's surfaces. Flow separations occur in two major areas. The critical flow separation affecting performance happens at the shroud near the blade leading edge. It also occurs at the blade suction side of the tip trailing edge. Figure 8 shows similar flow traces for impeller B\#2's surfaces. The B\#2 impeller also has the shroud separation; however, the suction-side separation vanishes. Table 1 compares the predicted power, the impeller (total) head, and the efficiency between the two impellers.

The predicted ShaftPWR for each impeller is lower than the targeted ShaftPWR (or PWR $\mathrm{Pef}_{\text {ref }}$. Although the B\#2 


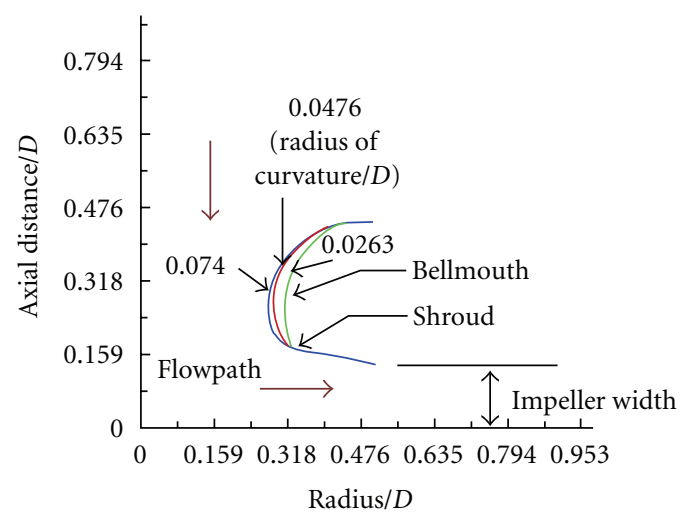

(a)

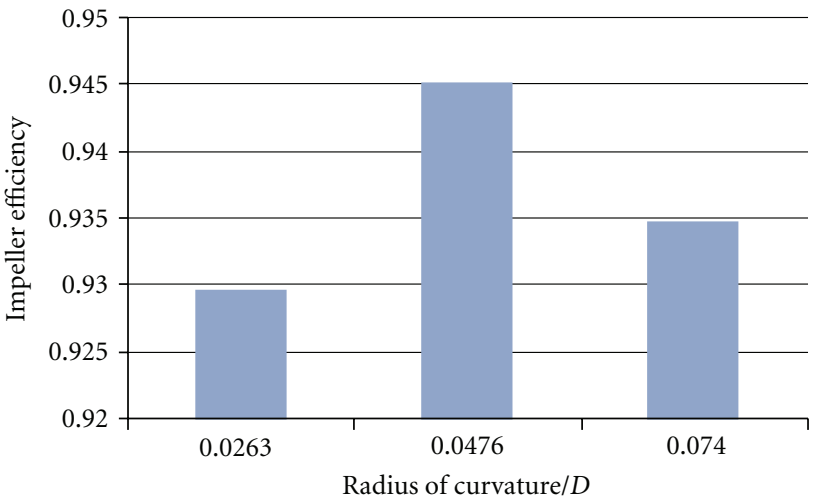

(b)

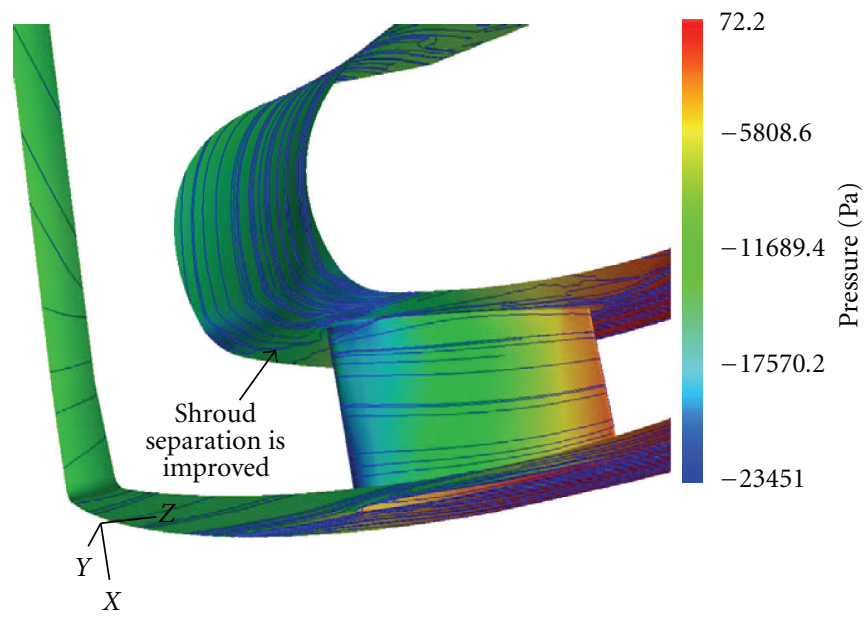

(c)

FIGURE 9: Based on the B\#2 impeller (a) bellmouth/shroud profiles investigated; (b) impeller performances; (c) improved separation for the 0.0476 shroud.

impeller requires more power at the specified condition, it generates more head and has a slightly higher efficiency. Since flow separation occurs in each impeller while operating at high efficiency, the redesign calculations must accurately account for all aerodynamic losses in order to predict any performance difference within a few percentage points. The use of streamline curvature or potential-flow/Euler codes would not accomplish the goals for the current redesign effort. The developed redesign procedures established based on the findings from the assessment of the existing impellers are herewith provided below.

\section{Impeller Aerodynamic Design}

3.1. Hub and Shroud/Bellmouth Designs. Since flow separations at the shroud in front of the blade leading edges were predicted for the two existing impellers, further improvement in impeller performance would require reducing this shroud flow separation. The large curvature of the shroud as it approaches the blade may be partially responsible for the flow separation seen at the shroud due to the difficulty of the boundary layer to remain attached as the flow negotiates the turn near the shroud. In Figure 9(a), three bellmouth/shroud profiles are presented and labelled based on the local curvature near the blade and shroud intersection. The profile labelled with 0.0263 (local radius of curvature $/ D$ ) corresponds to the $\mathrm{B} \# 2$ impeller. The two other profiles were investigated to reduce the sharp curvature at the blade intersection [13]. The associated flow fields of all three profiles indicate that the original flow separation at the shroud was improved in the two new profiles. Figure 9(c) demonstrates the improvement of the impeller with the 0.0476 shroud as compared to the B\#2 impeller shown in Figure 8. The performance data shown in Figure 9(b) suggests that the shroud labelled with 0.0476 provides the largest gain in efficiency. Although the required power for the 0.0476 shroud is slightly increased, it is used in the final design.

CFD prediction results were also made for the 11bladed B\#2 impeller, which was constructed based on the 12-bladed impeller to maintain a constant throat area, that is, at the location with the maximum blade thickness. The advantage of adapting the 11 blade arrangement is to reduce ShaftPWR by $2.38 \%$ for the impeller with the 0.0476 shroud as compared with the 12-bladed impeller with the same shroud curvature. Although a drop of $2.14 \%$ in total head for 


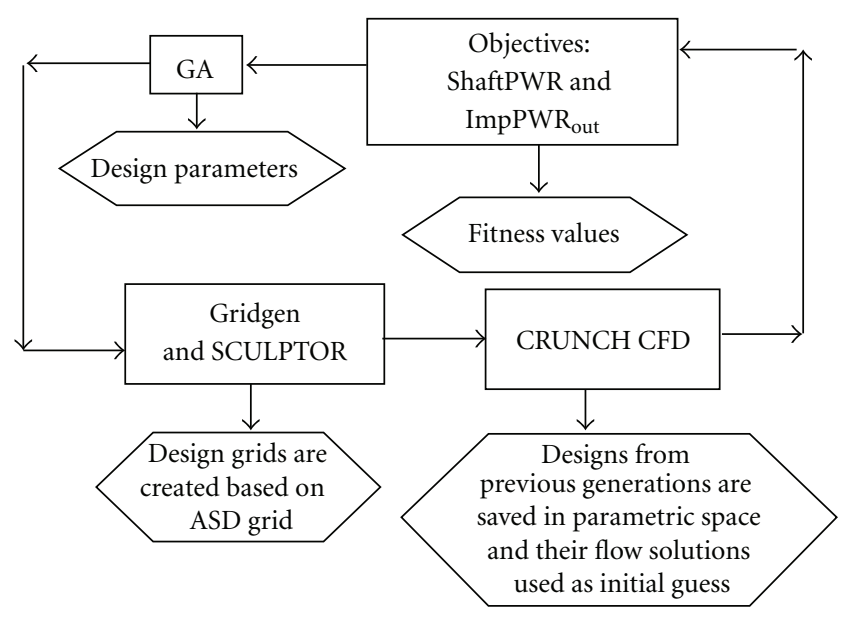

FIgURE 10: Flowchart for blade optimization.

the latter impeller occurred, the efficiency was maintained. These results led to the decision to choose the 11-bladed 0.0476 shroud profile impeller configuration. In addition, this modification required a blade redesign to recover the drop in the total head.

3.2. 2D Blade Profile Optimization. A GA-based procedure was used for optimization of the impeller blade. Since impeller B\#2's blade performs better than the B\#1 impeller as shown in the last section, the $\mathrm{B} \# 2$ blade shape was used as the starting geometry and all changes to the blade shapes were made through a network of Bezier curves. The GA uses the traditional selection, crossover, and mutation operators, whose implementation details are provided in [14]. A schematic of the design optimization framework is shown in Figure 10. Variables that represent deformation of the blade shape by moving the control points were passed by the GA to SCULPTOR where the shape modifications and grid alterations were performed. The grids were then passed to CRUNCH CFD and the performance of the altered designs was evaluated. The performance metrics in the form of the objective functions were passed back to the GA for the next design iteration.

The blade shapes were defined by a complex network control points which form an arbitrary shape deformation (ASD) grid (Figure 11(a)) that was generated utilizing the SCULPTOR tool. The blade shape was parameterized by 10 design variables of 5 control points ( 5 design variables on the pressure side and 5 design variables on the suction side shown in Figures 11(b) and 11(c)). The grouping of control points was implemented in the spanwise direction to ensure that the integrity of the $2 \mathrm{D}$ shape was maintained. GRIDGEN was used to generate the initial CFD grid for the original blade shape and subsequent grids were automatically generated with shape deformation propagating through the grids. The deformation was performed on a 2D airfoil shape and maintained along the spanwise direction. Furthermore the deformation was propagated to the grid points of the
CFD grid associated with the newly deformed blade shape within SCULPTOR.

The design requirements called for improving the efficiency of lift fan while meeting the set design criteria for the output fluid power delivered by the impeller. Conventionally, design optimization can be carried out for such a problem by either performing a multiobjective optimization or by using constraints to limit the shaft power and to maximize the output power. We utilized a mathematical function that was a combination of a target efficiency (95\%) and a target power requirement as an objective function. CRUNCH CFD calculated flow parameters as presented in (4)-(6). The objective of the GA was to measure the distance from a target ShaftPWR and output power, that is,

$$
d_{\mathrm{obj}}=\frac{\sqrt{(\text { ShaftPWR }-581)^{2}+\left(\mathrm{ImpPWR}_{\mathrm{out}}-552\right)^{2}}}{\mathrm{PWR}_{\mathrm{ref}}} .
$$

For this case, the targeted ShaftPWR and output power were set at 581 and $552 \mathrm{kWs}$, respectively. The objective function was set to compare impeller B\#1's performance data of 603.3 and $558.5 \mathrm{kWs}$, which has an impeller efficiency of $92.6 \%$ as described previously. The optimization calculation was to minimize this objective function. Due to the time constraint during the design phase, a total of 48 designs were analyzed during the design iterations. In Figure 12, the impeller total head generated and efficiency associated with each blade design during the 6 generation calculations are plotted in black diamond symbols versus the shaft power. The impeller head is nearly linear in relationship to the shaft power. The shaft power values for the $\mathrm{B} \# 1$ impeller and the design power threshold of $4.7 \%$ and goal of $10 \%$ reduction are also marked in each plot. The selected 2D blade shape, circled in the solid black circle in Figure 12, has a near peak fitness value plotted in Figure 13 and the highest efficiency in Figure 12 among all GA designs. The fitness plot in Figure 13 is an inverse measurement of the defined objective function shown in (7). The final unconventional 2D design from the GA design iteration is shown in Figure 14. The increased loading of the blade near midchord resulted in flow acceleration especially near the shroud where the original blades were prone to a large area of flow separation. This blade shape generated a total head of $1.459 P_{\text {ref }}$ at $93.68 \%$ efficiency and requires a shaft power of $0.926 \mathrm{PWR}_{\text {ref }}$. Some small modifications were made to the $2 \mathrm{D}$ blade through a steering process followed by the construction of a 3D blade by sweeping the $2 \mathrm{D}$ sections. The steering process and $3 \mathrm{D}$ blade construction is discussed in the following sections. The prediction results for all these later modifications are also plotted in Figures 12 and 13 as "Non-GA" points. After the final 3D modification, the fitness and efficiency are further improved from those obtained for the 2D blade design by GA. The peak of the "Non-GA" points in Figure 13 was not selected due to the aggressiveness of the design which will be described in the next section.

3.3. Steering of Blade Shape. The 2D blade cross-section design described in the previous section was performed in a relatively conservative manner due to an "unknown" cou- 


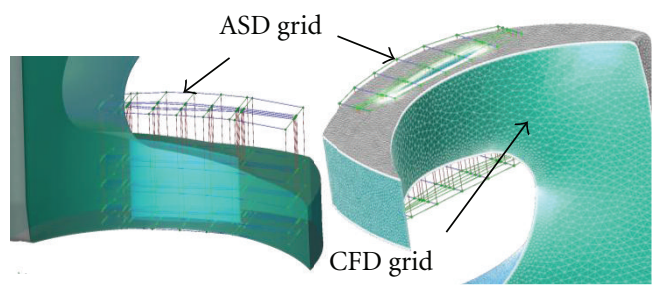

(a)

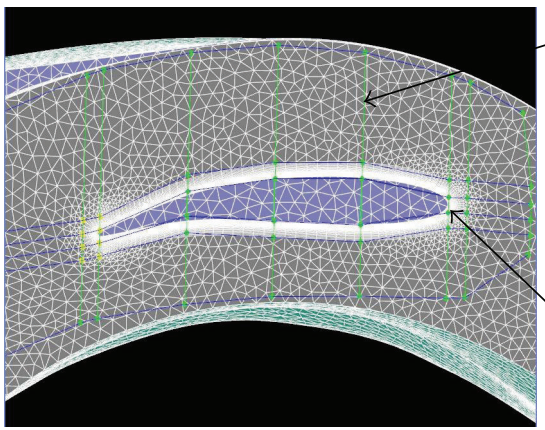

(b)

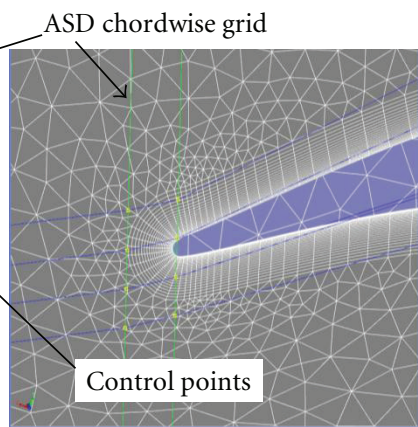

(c)

FIGURE 11: Blade design parameters are defined with ASD grid (a) a 3D view; (b) a chordwise view with a deformed blade; (c) a close-up view at the trailing-edge region of the deformed blade.

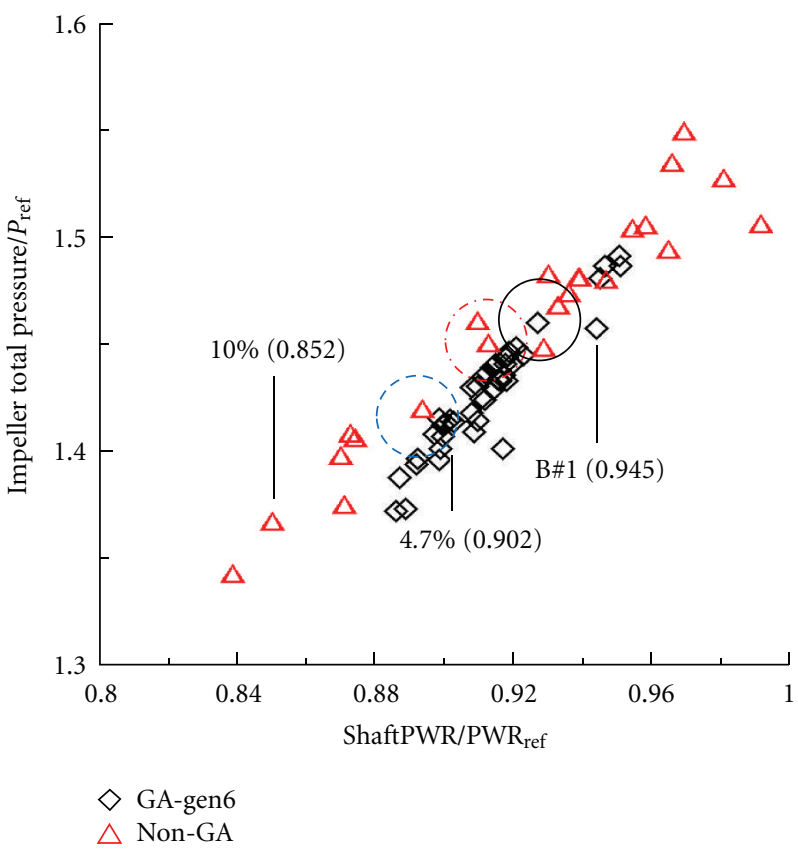

(a)

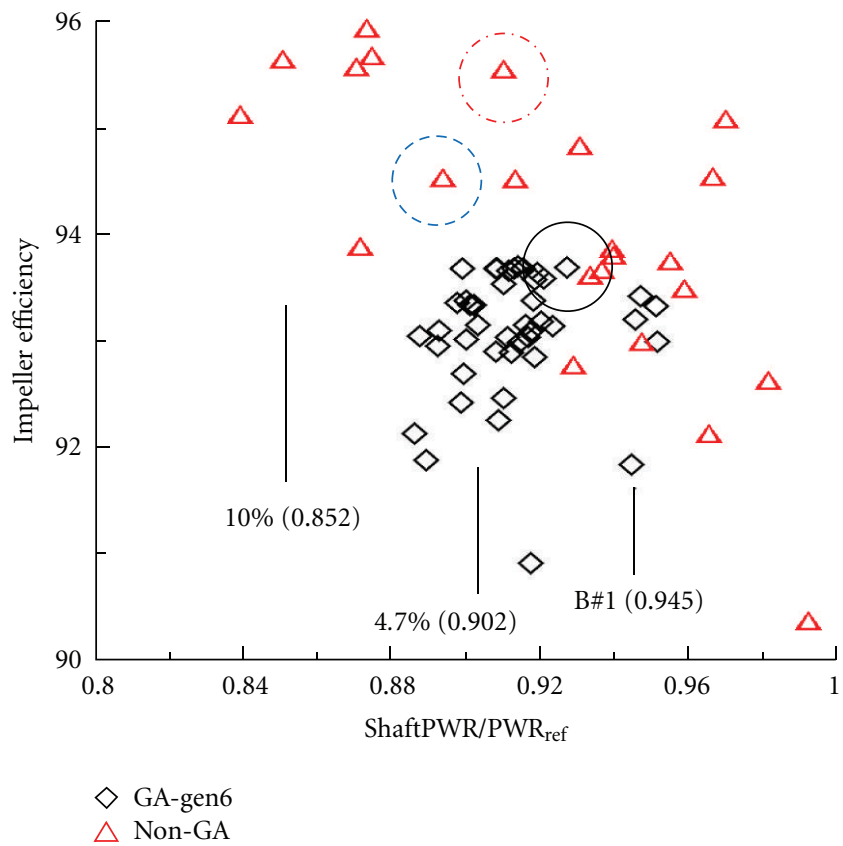

(b)

FIGURE 12: Landscape of optimization process in total pressure and efficiency versus ShaftPWR (black solid circle indicates result obtained from 2D design, blue dash circle is from 2D steering, and red dash-dot circle is from 3D design).

pling effect from the downstream volute. In addition, the period of the design phase was limited. In order to further enhance the gain in reducing the shaft power, a trailingedge modification was adapted. Since the blade trailing edges are placed at the maximum velocity region of the entire fan flow field, the effect of modifying the trailing-edge shape can be dramatic. Figure 15 demonstrates two steering profiles, that is, steer blade- 1 and steer blade, with minor changes in their trailing-edge profiles (i.e., trailing-edge angle to reduce blade turning) from the 2D design blade. The calculated shaft power, total head, and efficiency are $0.870 \mathrm{PWR}_{\text {ref }}, 1.376 P_{\text {ref }}$, and $93.87 \%$ for the steer blade-1; $0.896 \mathrm{PWR}_{\text {ref }}, 1.414 P_{\text {ref }}$, and $93.8 \%$ for the steer blade. The impeller efficiencies of the two steer blades and the 2D design blade are almost identical. 


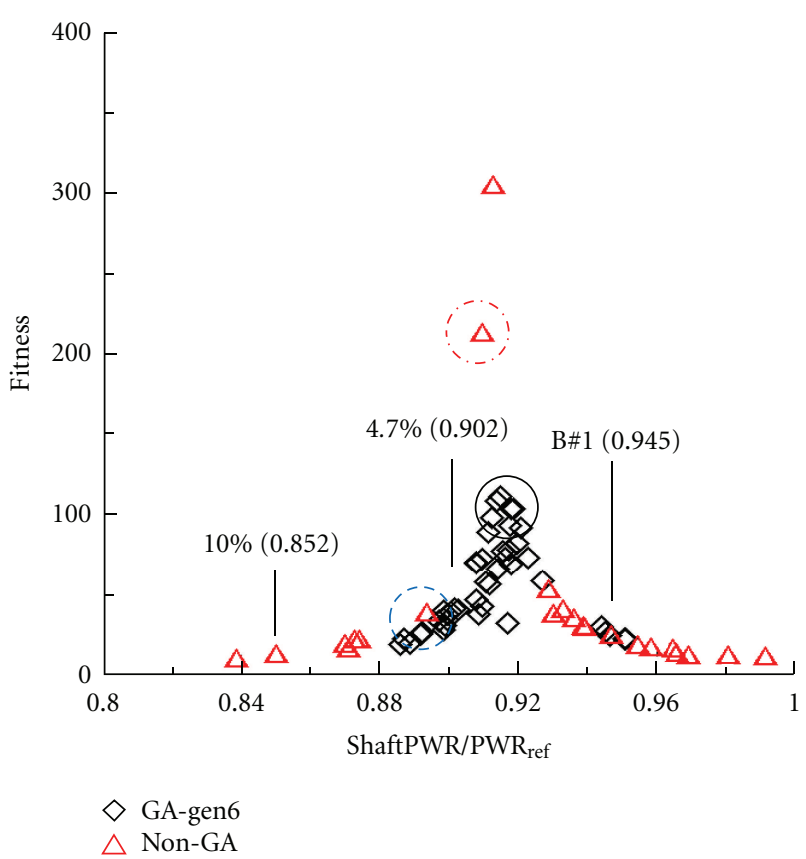

FIGURE 13: Fitness versus shaft power during design calculations.

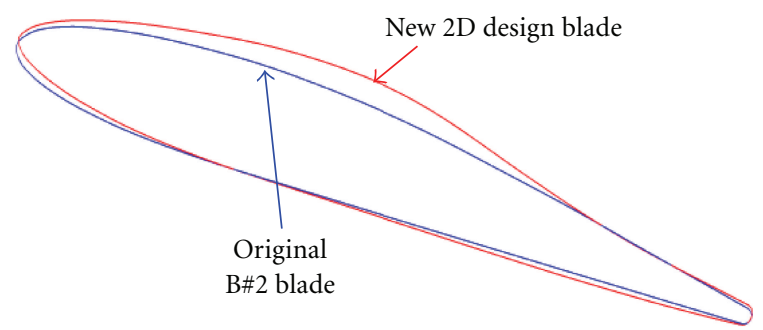

Figure 14: Blade shape obtained from 2D blade design optimization.

Even though the steer blade-1 required much lower shaft power, it unfortunately delivered much less head and output power. The steer blade-1 was considered too aggressive in meeting the requirement; therefore, the more conservative steer blade was chosen for further investigation.

3.4. 3D Swept Blade Design. Both existing impeller's blades were primarily $2 \mathrm{D}$ blades, that is, the leading and trailing edges at hub and shroud started at the same radii. The blade was designed as a 2D blade to reduce the manufacturing cost. There are some advantages to sweeping the blade: (i) a blade starting at a lower radius near the shroud can prevent boundary-layer separation by accelerating the flow before it actually turns, and (ii) it changes in incidence at the leading edge attributed to the sweep can lower losses and increase efficiency. Based on this concept, the B\#2 11-bladed impeller blades were extended inward radially at the leading edge and its angle measured from the shroud was modified from 0 degree for a 2D blade like the B\#1 blade to 10 degrees. The new 3D blade generated high head of $1.548 P_{\text {ref }}$ versus $1.471 P_{\text {ref }}$ with a higher efficiency of $95.08 \%$ versus $93.66 \%$

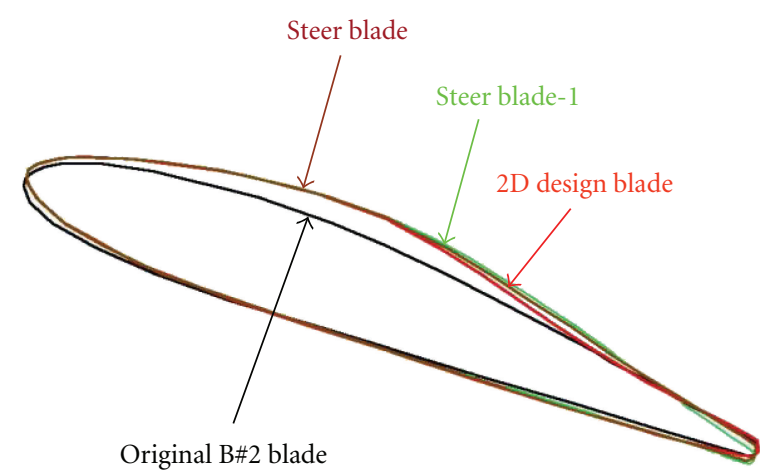

FIGURE 15: Blade shape obtained from 2D blade steering.

at the expense of a higher shaft power of $0.968 \mathrm{PWR}_{\text {ref }}$ versus $0.936 \mathrm{PWR}_{\text {ref. }}$ This procedure essentially improves the blade efficiency. When the same procedure was applied to the steer blade shown in Figure 15, the efficiency improved from 93.8 to $95.55 \%$, the head increased from $1.414 P_{\text {ref }}$ to $1.459 P_{\text {ref }}$ with the shaft power also increasing from $0.896 \mathrm{PWR}_{\text {ref }}$ to $0.909 \mathrm{PWR}_{\text {ref }}$. From here on out, when this $3 \mathrm{D}$ version of the steer blade is integrated with the impeller, it is referred to as the NEW design impeller.

3.5. Impeller Width Control. Impeller width is defined in Figure 9 as the distance between the backplate and the shroud. It represents the blade trailing-edge span with the shroud terminating at the blade trailing edge. Given the impeller diameter and the flow rate, this parameter controls the maximum achievable flow velocity. The widths for the two existing impellers shown in Figure 2 are $0.1207 \mathrm{D}$ and $0.1350 \mathrm{D}$, respectively.

The width of the NEW impeller is determined by starting with the B\#2 impeller width. Figure 16 shows the effects of the total pressure generated and the efficiency when changing the impeller width for the 11-bladed B\#2 (B\#2-11) impeller and the NEW impeller. Also shown in Figure 16 is the performance data from the B\#1 and B\#2 impellers. Derived from the $\mathrm{B} \# 2$ blading, a nearly linear performance was identified for the predicted shaft power (shown in [13]) and total head. Unlike the other parameters mentioned above, the efficiency seems to be independent of the width change. By adjusting the impeller width, the impeller total pressure can be controlled without sacrificing the performance. In other words, the NEW impeller generates less total head with the same width as the B\#1 impeller; however, with increased width, the NEW impeller is able to produce the same total head as the B\#1 impeller. Conversely, for a fixed impeller width, altering the blade geometry can play an important role in lowering shaft power and increasing impeller efficiency.

Similar improvement in the compressor performance by increasing the volute inlet width was reported by Kim et al. [15]. It should be noted that the volute inlet width was the same as the impeller width in their study. Note that the current volute inlet has a sudden expansion (shown in Figure 3) from the impeller exit versus Kim's volute which has a smooth connection between the volute and the 


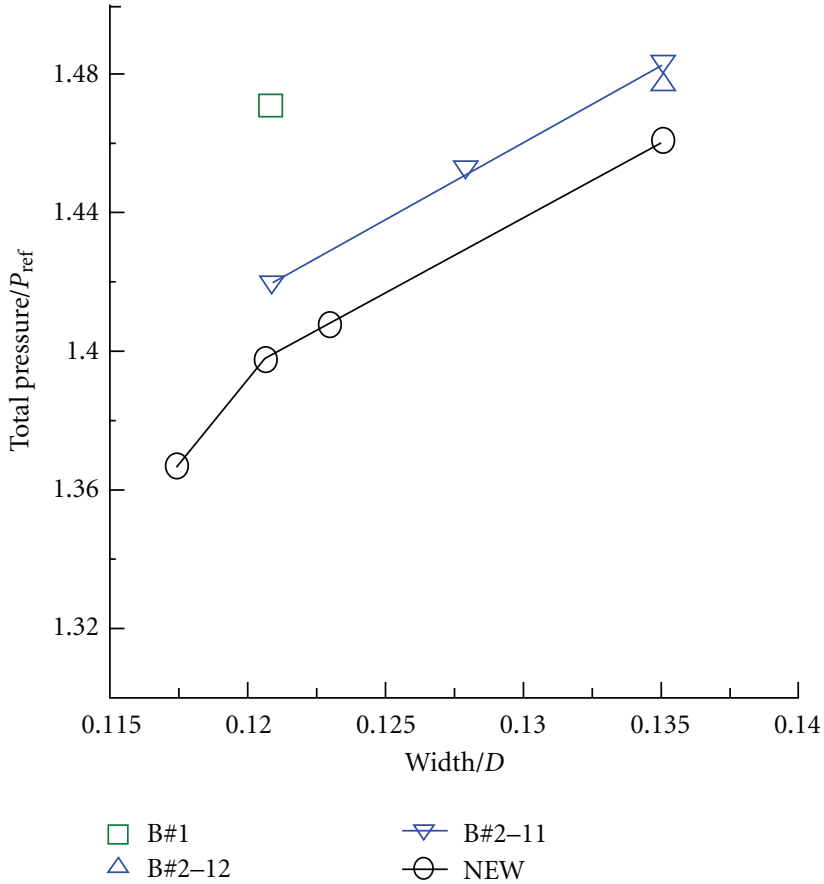

(a)

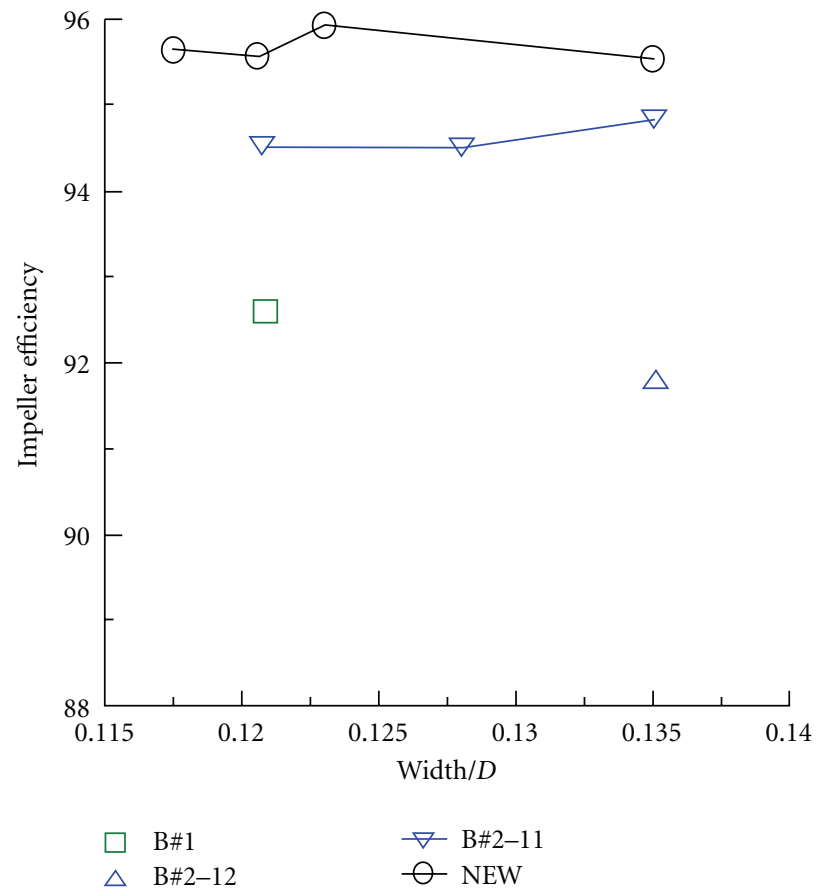

(b)

FIGURE 16: Effects on performance from changing the impeller width.

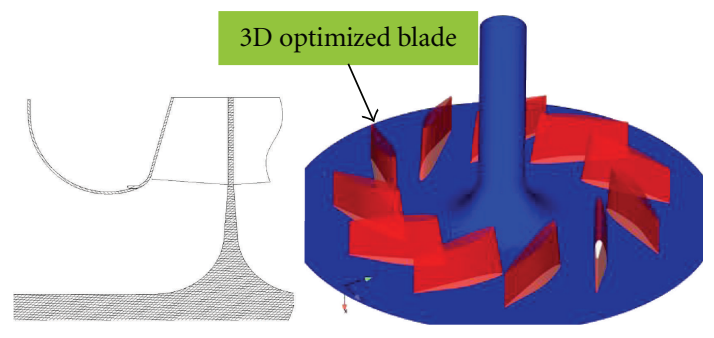

FIgURE 17: The integrated new design impeller NEW.

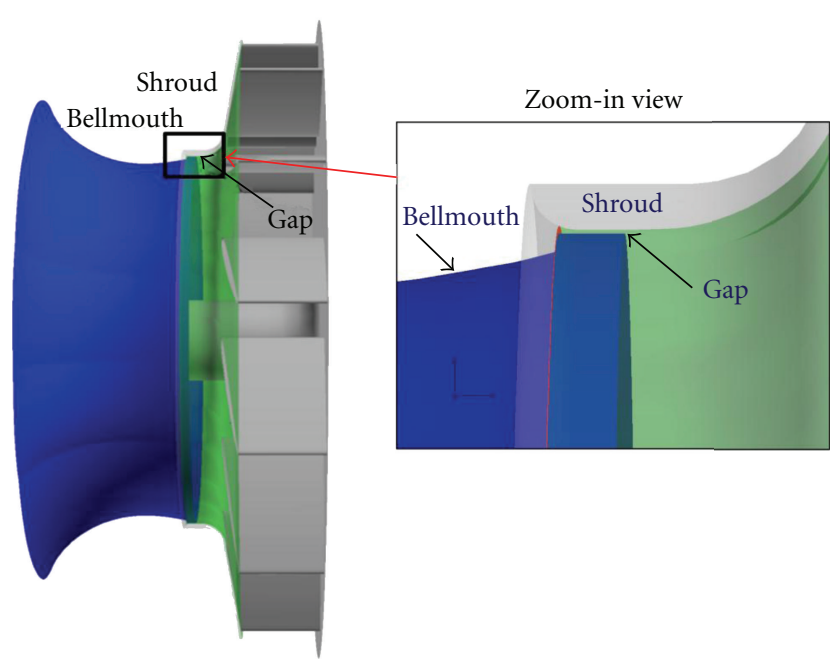

FIGURE 18: Gap and shroud configuration for B\#1 impeller.

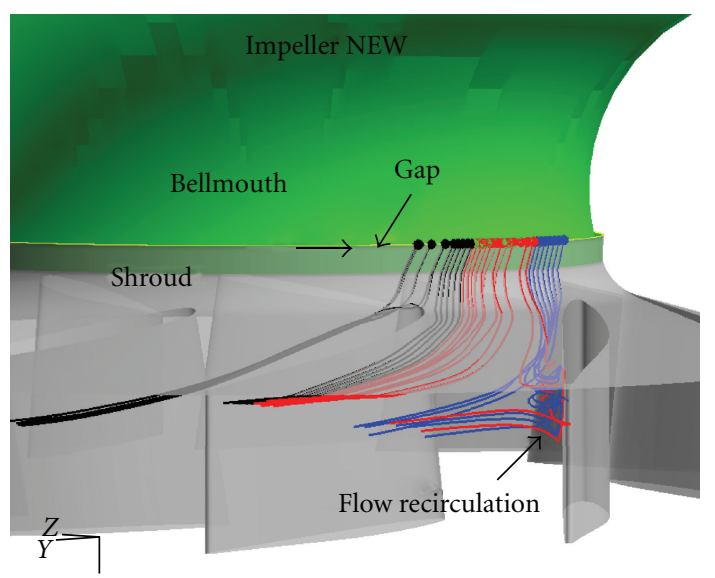

FIGURE 19: Streamlines initiating at the gap produce trailing-edge flow separation.

impeller. Before the diffused fluid started separating at the hub while the impeller width was increased, Kim et al. [15] also recorded increased head and a slight efficiency increase.

By integrating all of the above findings, which include the effects from the hub and bellmouth/shroud design, the 2D blade profile optimization, the steering of blade shape, the 3D swept blade design, and the impeller width control, an assembled impeller is shown in Figure 17 with eleven 3D blades. The width for the NEW impeller was chosen to be $0.1213 \mathrm{D}$. 


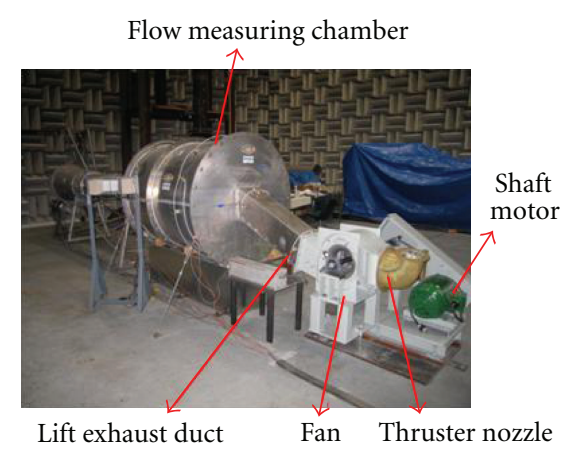

Figure 20: Centrifugal fan test rig.

\section{Prediction of Fan Performance}

4.1. Computational Method for Fan Flow Field. In order to evaluate the fan performance, it is necessary to include the volute with each impeller. Since the volute outer casing configuration is a structural constraint, it stays the same for all fans, the volute flow field and its feedback to the impeller are modified for changes in the impeller exit conditions and the volute-side's bellmouth and shroud shapes.

The impeller flow field is unsteady and periodic due to the interaction between each blade and the asymmetric volute casing (Figure 2), particularly at the two tongue locations. This time-varying flow field could be approximated by a time-averaged or steady flow field with a fixed geometric relationship between the impeller and the volute. This simplification is referred to as the frozen impeller approach. It computes the entire (all blades included) impeller steady flow field in the rotational frame and converts the flow field information to a stationary frame at an interface near the impeller exit to the downstream volute. The steady nonrotating volute flow is calculated from the interface to each volute exit. The conditions at the interface serve as information exchange between the impeller and the volute and are obtained as a part of the solution. The process is accomplished by convergence of key quantities such as the total pressures and mass flow rates at the impeller inlet, interface, and volute outlets.

For the impeller-flow calculation, all boundary conditions used for the CFD design calculations were maintained except for eliminating the periodic boundary condition and controlling the exit back pressure through the interface information exchange. For the volute-flow calculation, the mass-averaged discharge pressures from the two exits are prescribed to keep (a) the required flow to the lift side, (b) the extended surface from the impeller backplate modelled as a symmetry plane, (c) the shroud as the rotating wall, and (d) all other casing surfaces as no-slip walls.

The fan performance parameters were evaluated differently from the impeller design calculation. The shaft power was calculated using (4) while $T_{\text {imp }}$ was obtained by integrating the torque from all the impeller blades. The fan output power and the total-to-total efficiency were calculated using the following formulae:

$$
\begin{gathered}
\text { FanPWR out }=\left[\left(\Delta P_{t}\right)_{\text {lift }} \cdot Q_{\text {lift }}+\left(\Delta P_{t}\right)_{\text {thruster }} \cdot Q_{\text {thruster }}\right], \\
\eta_{\text {fan }}=\frac{\text { FanPWR }}{\text { ShaftPWR }} .
\end{gathered}
$$

There are two other parameters related to the lift-side performance. They are lift-side total and static efficiencies, which were calculated as follows:

$$
\left(\eta_{t}\right)_{\text {lift }}=\frac{\left(\Delta P_{t}\right)_{\text {lift }} \cdot Q_{\text {lift }}}{\text { ShaftPWR }}
$$

$$
\left(\eta_{s}\right)_{\text {lift }}=\frac{\left(\Delta P_{s}\right)_{\text {lift }} \cdot Q_{\text {lift }}}{\text { ShaftPWR }}
$$

The grid topology used for the impeller design calculation shown in Figure 5 was maintained. Depending on the number of blades designed for each fan, the total impeller grid was approximately 3 to 4 million cells. The corresponding volute for each fan had approximately 1.5 million cells. The converged volute solution for the baseline B\#1 impeller was first obtained by adjusting the pressures at the two exits to reach the design lift flowrate. Similar exit pressures were applied for all other impeller calculations to obtain the lift flowrates shown in Tables 2 and 3.

4.2. Impeller/Volute Coupling Solutions. Table 2 shows the performance data obtained from the impeller/volute coupling calculations for all fans. Adapted from the grid topology used for the impeller design CFD, the impeller grid ended at a fixed radius for all coupling calculations except for the NEW impeller, which ended at a slightly smaller radius. In order to compare the performance with similar grid features for all fans, the NEW-x grid was generated by radially extending the shroud of the NEW impeller. Since the impeller width plays an essential role in the impeller performance, a wider width impeller was generated for comparison and is labelled as the NEW-w impeller.

In addition, the fan total-to-total efficiency is calculated in Table 2 using (8) and (9). The lift-side static and total pressures, along with their efficiencies are also tabulated. The volute losses (column "Loss") at the lift side were estimated by subtracting the lift-side total pressure from the impeller head $\left(\operatorname{del} P_{t}\right)$.

It is interesting to note that the $\mathrm{B} \# 2$ impeller now requires less shaft power $(0.8 \%)$ than the $\mathrm{B} \# 1$ impeller. The NEW impeller reduces shaft power by $5.76 \%$ from the baseline. When the volute was coupled with the impeller, the impeller efficiency for the NEW impeller dropped from the impellerdesign prediction of $95.5 \%$ to $89 \%$. Similar reductions were predicted for the B\#1 and B\#2 impellers, that is, from $93 \%$ to $88 \%$. A total drop of five to six percentage points in the impeller efficiency with the volute feedback is considered. When the losses in the volute were included, the total fan efficiency further reduced to between $76.9 \%$ and $78.3 \%$ for all fans except the B\#2 impeller which decreased to $74 \%$. The dramatic reduction in the volute loss for the NEW impeller 


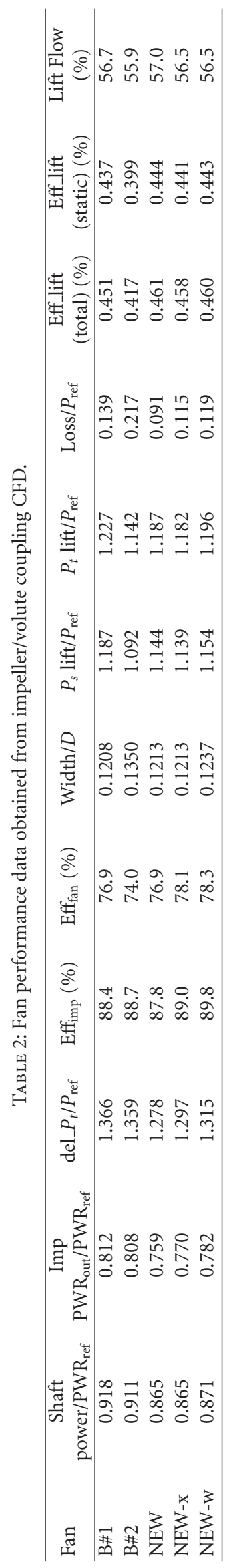




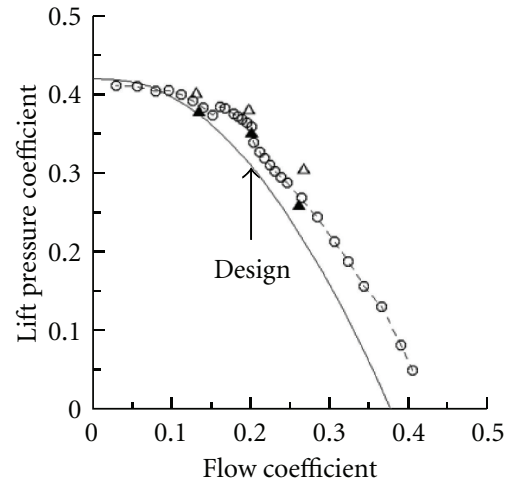

Impeller B\#1

— Requirement

- $\bullet$ - B\#1 model test (5212 rpm)

$\triangle \quad \mathrm{B} \# 1$ CFD (FS)

- B\#1 CFD (MS)

(a)

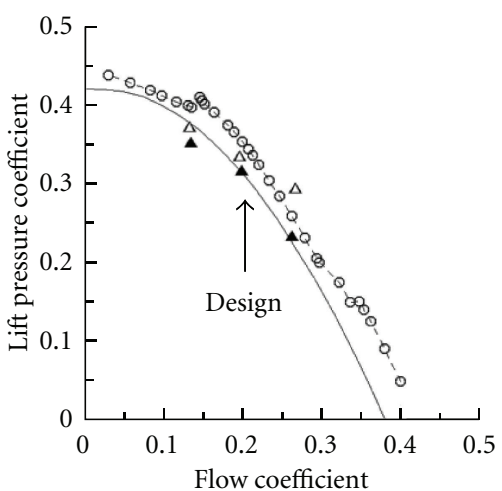

Impeller B\#2

$$
\begin{aligned}
& \text { — } \text { Requirement } \\
& -\ominus-\text { B\#2 model test }(5212 \mathrm{rpm}) \\
& \triangle \quad \mathrm{B} \# 2 \text { CFD (FS) } \\
& \triangle \mathrm{B} \# 2 \text { CFD (MS) }
\end{aligned}
$$

(b)

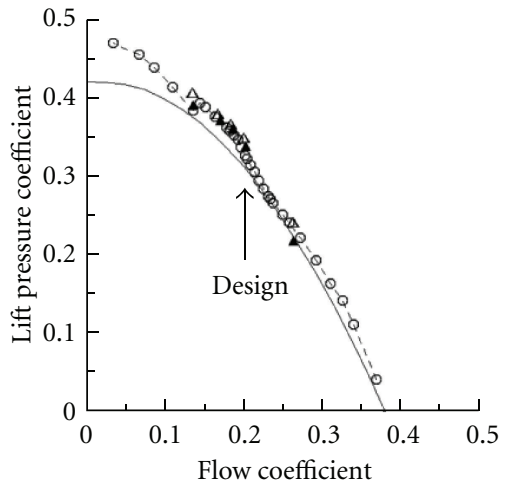

Impeller NEW
$\begin{aligned} & \text { — } \\ & \text { - }\end{aligned}$ NEquirement
$\Delta \quad$ NEW CFD (FS)
$\Delta \quad$ NEW CFD (MS)

(c)

FIGURE 21: Measured lift pressure coefficient compared with the requirement and CFD predictions for the B\#1, B\#2, and NEW impellers.

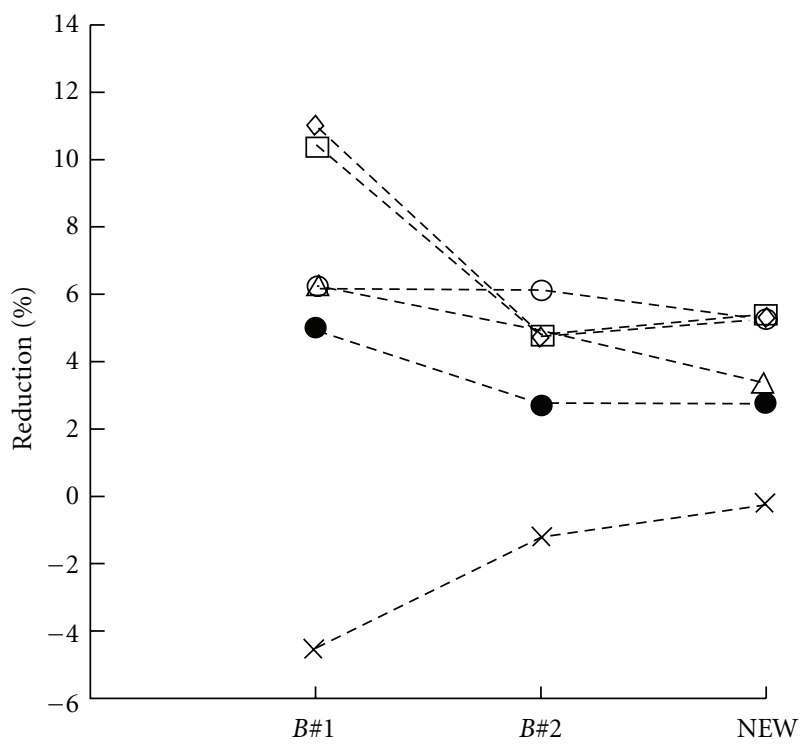

$\begin{array}{ll}\text { Rey_No_Effect } & \\ - \text { - ShaftPWR } & -\diamond-\text { Lift_Ps } \\ -\Theta-\text { OutPWR } & -\square-\text { Lift_Pt } \\ -\triangle-\text { Fan_Eff } & -\rtimes-\text { Volute_Loss }\end{array}$

Figure 22: Predicted impact of model fan's lower Re number on fan performance for the existing and new fans.

suggests that the exit flow from the new impeller matches better with the downstream volute flow than those for the existing impellers. In summary, the NEW impeller improves fan efficiency by 1.2 percentage points and reduces power by $5.8 \%$.

Although the calculated static pressures are all higher than the required lift-side discharge pressure $\left(P_{s} / P_{\text {ref }}>1\right)$, the air static pressures at the lift side for both NEW and B\#2 impellers are lower than that of the B\#1 impeller. As shown in current predictions, the NEW impeller can meet the lift pressure and power reduction requirements if the existing B\#1 impeller is overpowered at the design condition.

4.3. Impeller/Volute Coupling Solutions with Shroud Gap Effect. The shroud gap between the stationary bellmouth and the rotating shroud is shown in Figure 18 for the B\#1 impeller. Using this refined geometry, the frozen impeller calculations included not only the narrow gap, but also the shroud thickness and its end shape. The gap sizes designed for the $\mathrm{B} \# 1, \mathrm{~B} \# 2$, and NEW impellers are $0.08 \%$, $0.15 \%$, and $0.08 \%$ of the impeller diameter, respectively. The shroud gap flow accounts for $0.52 \%, 0.92 \%$, and $0.58 \%$ of the inflow at the design condition for the three impellers. Table 3 provides the performance data at the design condition for the three impellers. Reference [16] provides further details for the effects of the gap on the impeller aerodynamics.

Comparing the data between Tables 2 and 3, the gap effect for the B\#1 impeller inversely affects performance as compared to the other two impellers. The $\mathrm{B} \# 2$ and NEW impellers suffer about $0.5 \%$ reduction in fan efficiency due to the gap-affected impeller exit flow [17] into the volute which induces impeller blade trailing-edge flow recirculation, as shown in Figure 19. In contrast, the shroud gap flow improves both the impeller and the fan efficiencies for the B\#1 impeller. This may have been caused by the unstable gap-flow solution using the current steady calculation procedure. The calculations including the gap further complicate the role of volute influences to the fan's overall performance. Tabular data provided in Table 3 for the $\mathrm{B} \# 2$ and NEW impellers also indicate the shaft powers are reduced by $6.0 \%$ and $8.7 \%$, respectively, as compared to the $\mathrm{B} \# 1$ impeller. 


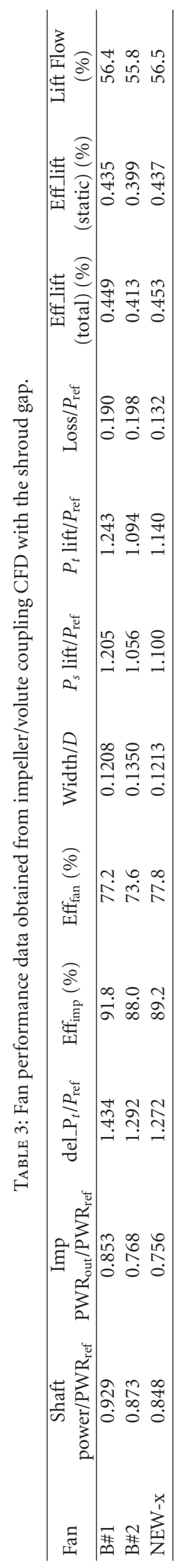




\section{Design Validation through Model Fan Test}

Test data for all three fans was collected from the 1/5-scale fan test rig as shown in Figure 20. The performance test setup was constructed using the American National Standards Institute (ANSI)/Air Movement and Control Association (AMCA) standards [8] as a reference. For model Reynolds number $(\mathrm{Re})$ to be similar to the full-scale value, the model test would ideally be run at 5-times the full-scale speed of $1692 \mathrm{rpm}$. Following the Re suggestion of Phelan et al. [18], Re based on $U$ and $D$ should be between $1.0 \times 10^{6}$ for the backward-swept centrifugal fans and $2.0 \times 10^{6}$ for airfoilbladed centrifugal fans to reach the Re independent regime. The current measurements were limited to a maximum impeller speed of $5212 \mathrm{rpm}$. For this case, the Re at this model operating condition is $1.8 \times 10^{6}$. The measured lift-side static pressure coefficient versus the lift-side flow coefficient is plotted in Figure 21 for the three impellers. The uncertainty of the measured pressure was estimated to be within $0.25 \%$ [8] at design conditions. Comparisons shown in Figure 21 include the original design required pressure rise, model test data, and CFD predictions for the full-scale (FS) and model-scale (MS) fans. The latter calculations for the MS fans were performed using the MS Re number, which is about $12 \%$ of the FS Re number. There existed a sudden pressure drop in all three fans at the point the fans went into stall conditions. For the B\#1 impeller, a sudden pressure rise exists near the design condition. This rise in pressure does not occur for the other two impellers. This phenomenon may be attributed to the fan testing conditions being close to the flow transition region, where separated and reattached flows were interchanged to affect the sudden pressure rise and drop.

CFD predictions shown in Figure 21 for the FS and MS fans clearly demonstrate the Re effect, which is larger for the $\mathrm{B} \# 1$ and $\mathrm{B} \# 2$ impellers than the NEW impeller. CFD results also include predictions using off-design flow rates. The MS CFD predictions agree well with the model test data for both B\#1 and NEW impellers, particularly the rise and fall for the NEW impeller. The CFD underpredicts the lift pressure for the B\#2 impeller which may have resulted from the deviation in geometry used for the calculations and the experiments. Figure 22 provides comparisons of the reductions in various fan performance parameters obtained from the differences between the MS and the FS fan calculations among three impellers. The NEW impeller has the smallest performance variation in almost all the parameters predicted, particularly for the volute losses as pointed out previously.

Comparing the design requirement with the measured data, it is obvious from Figure 21 that both impellers B\#1 and $\mathrm{B} \# 2$ generate more-than-required pressure at the volute lift-side discharge. This verifies the conclusion obtained in the previous section and confirms the feasibility of further reducing power consumption. Specifically, the measured liftside pressures for the $\mathrm{B} \# 1, \mathrm{~B} \# 2$, and NEW impellers are $13.8 \%, 9.6 \%$, and $3.7 \%$ higher than the required pressure (shown in (2)) at the design condition, respectively. Similarly, the measured power reductions for the three impellers at the design condition are $5.7 \%, 7.8 \%$, and $14.0 \%$ lower than the required power shown in (3), respectively. In other words, the B\#2 and NEW impellers reduce the shaft power by $2.2 \%$ and $8.8 \%$, respectively, in comparison with the B\#1 impeller. The NEW impeller has achieved twice the amount of power reduction from the baseline B\#1 impeller and agrees well with the CFD predictions shown in the last section.

\section{Summary and Conclusion}

A double-inlet, double-width impeller was modified to fit into a baseline double-discharge volute for a centrifugal fan. The goal was to reduce power consumption while maintaining a specified output pressure at the lift-side volute exit. The design modification was completed by decoupling the impeller from the volute. Using the developed design strategy, the following results are identified.

(i) The impeller-only calculations for the baseline B\#1 impeller and the reference $\mathrm{B} \# 2$ impeller indicate that the total efficiencies of both existing impellers are high (above 92\%). This suggests that conventional design methods such as a streamline curvature or an inviscid calculation method would be inadequate in addressing any aerodynamic improvements to the existing impellers. In addition, a computational method accounting for all the aerodynamic losses is required.

(ii) The flow turning area from the axial to the radial direction in front of the blade leading edge is required to be adequately designed to avoid the shroud flow separation. A blade leading-edge extension and sweep into the shroud turning area prevents the air from separating from the shroud surface and improves the impeller's efficiency. This allows the 14-bladed baseline B\#1 impeller to be redesigned as the 11bladed NEW impeller.

(iii) The $2 \mathrm{D}$ blade profile optimization, based on a numerical coupling between a CFD calculation and a genetic algorithm optimization scheme, is able to achieve a composite objective with a projected shaft power and a power output. The optimization improves the impeller efficiency from $92.6 \%$ to $93.7 \%$.

(iv) Blade trailing-edge shape control (or blade steering) effectively modifies the impeller exit flow and reduces power (from 0.945 to $0.896 \mathrm{PWR}_{\text {ref }}$ or a $31.3 \mathrm{~kW}$ reduction) while maintaining efficiency.

(v) The width of the impeller is almost linearly related to the impeller total head generated. However, the impeller efficiency remains nearly constant while the width changes.

The CFD calculations for evaluating the fan performance were performed using a frozen impeller approach to compute the steady flows throughout the impeller and the volute. CFD predictions were validated with the measurements. The conclusions drawn from the comparisons are as follows. 
(i) Volute feedback to the impeller reduces impeller efficiency by five to six percentage points from the original range of $93-95 \%$. Fan efficiency is further reduced to the $74-78 \%$ range by including the volute losses. The matching volute design plays an important role in determining fan efficiency, which is improved by $1.2 \%$ for the new fan over the baseline fan.

$P_{\text {ref }}: \quad$ Reference pressure, $7517 \mathrm{~Pa}$

Q: $\quad$ Flow rate

Re: $\quad$ Reynolds number

ShaftPWR: Shaft power

$\mathrm{PWR}_{\mathrm{ref}}$ : Reference power, $638.3 \mathrm{~kW}$

$t: \quad$ Time

$T: \quad$ Impeller torque

U: $\quad$ Fan tip speed $(141.77 \mathrm{~m} / \mathrm{s} @$ design

(ii) The shroud gap between the bellmouth and the shroud carries less than $1 \%$ of the inflow back from the volute to the impeller for the current fans. It also reduces fan efficiency by $0.5 \%$. Although the gap flow alleviates the shroud flow separation, it affects the blade trailing-edge flow, particularly at the volute tongue locations.

(iii) The test data of the lift-side pressure rise for the existing and new impellers agrees well with the CFD predictions based on the model Reynolds number. The CFD predictions suggest that a Reynolds number effect exists between the model- and full-scale fans. This Reynolds number effect is larger for the existing impellers as compared to the new impeller.

(iv) The comparisons between the CFD predictions and measurements confirm that the existing fan was overpowered at design, which enabled a new impeller design with a lower power requirement. The measured power reduction for the new impeller is $8.8 \%$ lower than the baseline. This reduction in power agrees with the $8.7 \%$ reduction obtained from the CFD predictions.

\section{Disclosure}

This material is declared a work of the U.S. Government and is not subject to copyright protection in the United States. Approved for public release; distribution is unlimited.

\section{Abbreviations}

$\begin{array}{ll}\text { ASD: } & \text { Arbitrary shape deformation } \\ \text { CRUNCH: } & \text { CFD code used in the present study } \\ D: & \text { Impeller diameter, } 1.6 \mathrm{~m} \\ \text { DDV: } & \text { Double discharge volute } \\ d_{\text {obj: }} & \text { Distance parameter used in defining the } \\ & \text { optimization objective function shown } \\ & \text { in }(7) \\ \text { DWDI: } & \text { Double-width, double-inlet fan type } \\ \text { FS: } & \text { Full scale } \\ \text { Fan_PWR } & \text { Fan output power defined in (8) } \\ \text { GA: } & \text { Genetic algorithm } \\ \text { Imp_PWR out }: & \text { Impeller output power defined in (5) } \\ k: & \text { Turbulent kinetic energy } \\ \text { B\#1, B\#2: } & \text { Baseline and reference impellers } \\ \text { MS: } & \text { Model scale } \\ \text { NEW: } & \text { New impeller } \\ P: & \text { Pressure }\end{array}$

\section{Subscripts}

thruster: Thruster side of the fan

imp: Impeller

lift: $\quad$ Lift side of the fan

out: Output

s: $\quad$ Static pressure

$t: \quad$ Total pressure.

\section{Acknowledgments}

This paper was funded by the Office of Naval Research, Code 331 as part of the lift-fan efforts of the Seabase-toShore FNC Program. The ONR Program Manager was Dr. Ki-Han Kim. This paper was prepared under the support of the Applied Research Program of the Office of Naval Research administered at the Naval Surface Warfare Center, Carderock Division under the IAR Program. The computational resources from the Naval Oceanographic Office Major Shared Resource Center (NAVOCEANO MSRC) were provided through the DoD High Performance Computing Modernization Program (HPCMP).

\section{References}

[1] L. Yun and A. Bliault, Theory and Design of Air Cushion Craft, Elsevier Butterworth-Heinemann 30 Corporate Drive, Burlington, Mass, USA, 2005.

[2] K. A. Kaupert and T. Staubli, "The unsteady pressure field in a high specific speed centrifugal pump impeller-part I: influence of the volute," Journal of Fluids Engineering, Transactions of the ASME, vol. 121, no. 3, pp. 621-626, 1999.

[3] K. Hillewaert and R. A. Van Den Braembussche, "Numerical simulation of impeller-volute interaction in centrifugal compressors," Journal of Turbomachinery, vol. 121, no. 3, pp. 603608, 1999.

[4] Y. T. Lee and T. W. Bein, "Performance evaluation of an airconditioning compressor-part II: volute flow predictions," International Journal of Rotating Machinery, vol. 5, no. 4, pp. 241-250, 1999. 
[5] T. Meakhail and S. O. Park, "A study of impeller-diffuservolute interaction in centrifugal fan," Journal of Turbomachinery, vol. 127, no. 1, pp. 84-90, 2005.

[6] A. Atif, S. Benmansour, and G. Bois, "Numerical investigation of velocity flow field inside an impeller air model of a centrifugal pump with vaned diffuser interactions and comparison with PIV measurements," International Journal of Rotating Machinery, vol. 2010, Article ID 706043, 12 pages, 2010.

[7] K. V. Karanth and N. Y. Sharma, "CFD analysis on the effect of radial gap on impeller-diffuser flow interaction as well as on the flow characteristics of a centrifugal fan," International Journal of Rotating Machinery, vol. 2009, Article ID 293508, 8 pages, 2009.

[8] M. E. Slipper, P. J. McGinnis, G. Choi et al., "Design and evaluation of high performance lift fan models for the landing craft, air cushion (LCAC)," Naval Surface Warfare Center Report NSWCCD-98-TR-2008, 2008.

[9] A. Hosangadi, R. A. Lee, B. J. York, N. Sinha, and S. M. Dash, "Upwind unstructured scheme for three-dimensiona combusting flows," Journal of Propulsion and Power, vol. 12, no. 3, pp. 494-502, 1996.

[10] A. Hosangadi, R. A. Lee, P. A. Cavallo, N. Sinha, and B. J. York, "Hybrid, viscous, unstructured mesh solver for propulsive applications," in Proceedings of the 34th Joint Propulsion Conference, AIAA-98-3153, Cleveland, Ohio, USA, 1998.

[11] T. J. Barth, "A 3D upwind euler solver for unstructured meshes," Paper No. AIAA-91-1548, 1991.

[12] T. J. Barth and S. W. Linton, "An unstructured mesh newton solution for compressible fluid flow and its parallel implementation," Paper No. AIAA-95-0221, 1995.

[13] Y. T. Lee, L. Mulvihill, R. Coleman et al., "LCAC lift fan redesign and CFD evaluation," Naval Surface Warfare Center Report NSWCCD-50-TR-2007/031, 2007.

[14] Y. T. Lee, V. Ahuja, A. Hosangadi, and M. Ebert, "Shape optimization of a multi-element foil using an evolutionary algorithm," Transactions of the ASME Journal of Fluids Engineering, vol. 132, no. 5, pp. 051401-1-051401-11, 2010.

[15] S. Kim, J. Park, K. Ahn, and J. Baek, "Improvement of the performance of a centrifugal compressor by modifying the volute inlet," ASME Journal of Fluids Engineering, vol. 132, pp. 091101-1-091101-7, 2010.

[16] Y. T. Lee, "Impact of fan gap flow on the centrifugal impeller aerodynamics," Transaction of ASME Journal of Fluids Engineering, vol. 132, pp. 091103-1-091103-9, 2010.

[17] A. Hildebrandt and M. Genrup, "Numerical investigation of the effect of different back sweep angle and exducer width on the impeller outlet flow pattern of a centrifugal compressor with vaneless diffuser," Journal of Turbomachinery, vol. 129, no. 2, pp. 421-433, 2007.

[18] J. J. Phelan, S. H. Russel, and W. C. Zeluff, "A study of the influence of reynolds number on the performance of centrifugal fans," ASME Paper No. 78-WA/PTC-1, 1978. 

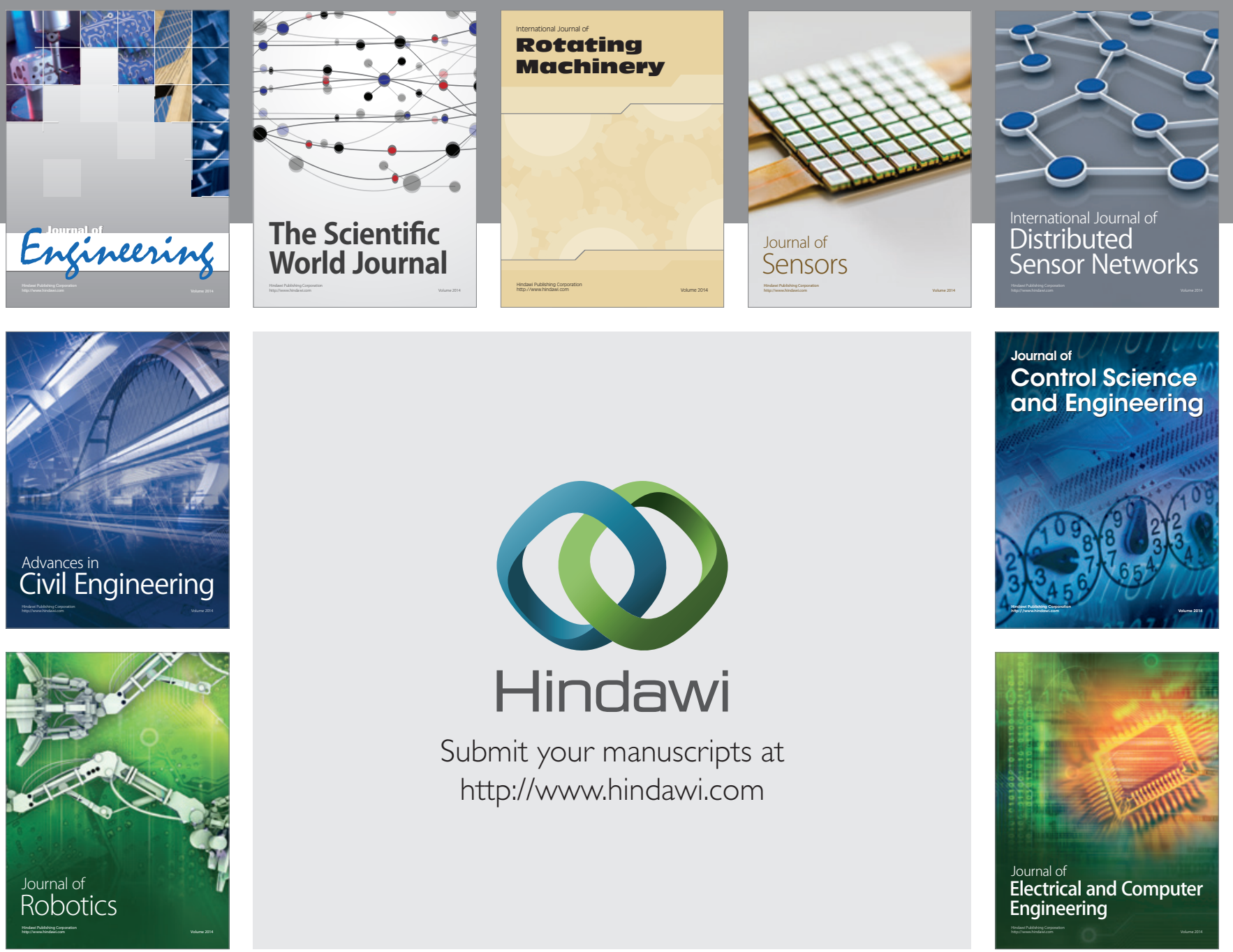

Submit your manuscripts at

http://www.hindawi.com
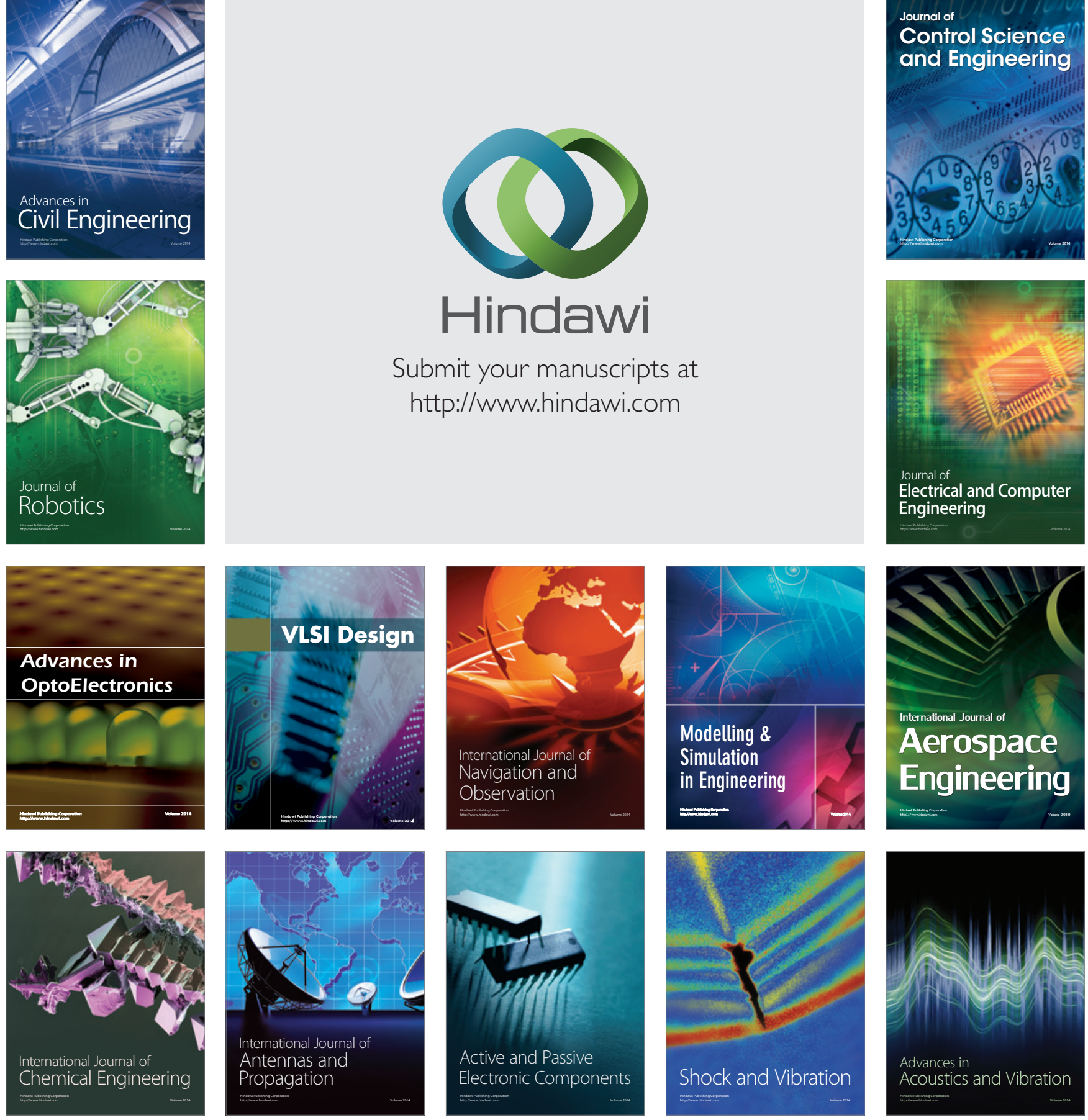